\title{
Warum wirkt die bariatrische Chirurgie eigentlich?
}

\author{
Die Gewichtsabnahme nach bariatrischer Chirurgie geht im Vergleich zu adipösen Personen \\ mit erheblichen Veränderungen fäkaler und zirkulierender Metaboliten einher. Dieses Studien- \\ ergebnis wirft auch eine neues Licht auf die Entstehung der Adipositas.
}

_ Die bariatrische Chirurgie ist gegenwärtig das effektivste Behandlungsverfahren bei Adipositas. Obwohl nicht ganz klar ist, was Henne und was Ei ist, scheint die Gewichtsabnahme nicht nur schlicht auf die reduzierte Kalorienaufnahme zurückzugehen. Vielmehr gibt es Hinweise auf metabolische Veränderungen, bei denen die Darmflora eine wichtige Rolle spielen könnte.

Die Stuhlproben von jeweils sieben Frauen, die sich 9,4 Jahre zuvor entweder einer Magenbypass-Operation (RYGB) oder einer Gastroplastie mittels Magenband (GB) unterzogen hatten, wurden mikrobiologisch und gentechnologisch untersucht. Als Vergleichsprobe diente der Stuhl von sieben adipösen Frauen mit einem ähnlichem BMI, wie ihn die operierten Frauen präoperativ gehabt hatten. Im Stuhl von Frauen mit RYGB kam es im Vergleich zu den anderen beiden Gruppen zu einem deutlichen Shift zugunsten von Proteobakterien bei gleichzeitiger Verringerung mehrerer Clostridien-Spezies.

Diese Veränderungen konnten nicht auf die bloße Tatsache einer Gewichtsabnahme zurückgeführt werden. So entwickelten Mäuse, denen Mikrobiota von Frauen mit Magenbypass übertragen wurde, eine geringere Fettmasse und hatten einen reduzierten respiratorischen Quotienten. Das spricht dafür, dass sich die kalorische Ausnutzung von Kohlenhydraten verringerte und vermehrt Fett für metabolische Prozesse verbraucht wurde. Offensichtlich kommt es nach einer Bypassoperation zu fundamentalen Veränderungen des Mikrobioms, die über lange Zeit hinweg anhalten und sich deutlich von Veränderun- gen nach diätetischen Interventionen zur Gewichtsabnahme unterscheiden.

- Tremaroli Vet al. Roux-en-Y gastric bypass and vertical ban ded gastroplasty induce long-term changes oft he human gut microbiome contributing to fat mass regulation. Cell Metab. 2015;22:228-38

\section{KOMMENTAR}

Die Untersuchung ist nicht nur eine mögliche Erklärung für den guten Effekt von Bypassoperationen auf das Körpergewicht. Sie wirft auch ein völlig neues Licht auf die Entstehung der Adipositas und erklärt, warum die "Friss die Hälfte"-Methode langfristig so wenig erfolgreich ist. Umgekehrt kennen wir alle Menschen, die sich überhaupt keinen diätetischen Restriktionen unterwerfen und dennoch lebenslang schlank bleiben. Vielleicht wird die Therapie der Adipositas in einigen Jahren völlig anders aussehen, als wir sie heute kennen.

Prof. Dr. med. H. S. FüeßI

\section{Juckende Erinnerungen ans Schnorcheln in der Karibik}

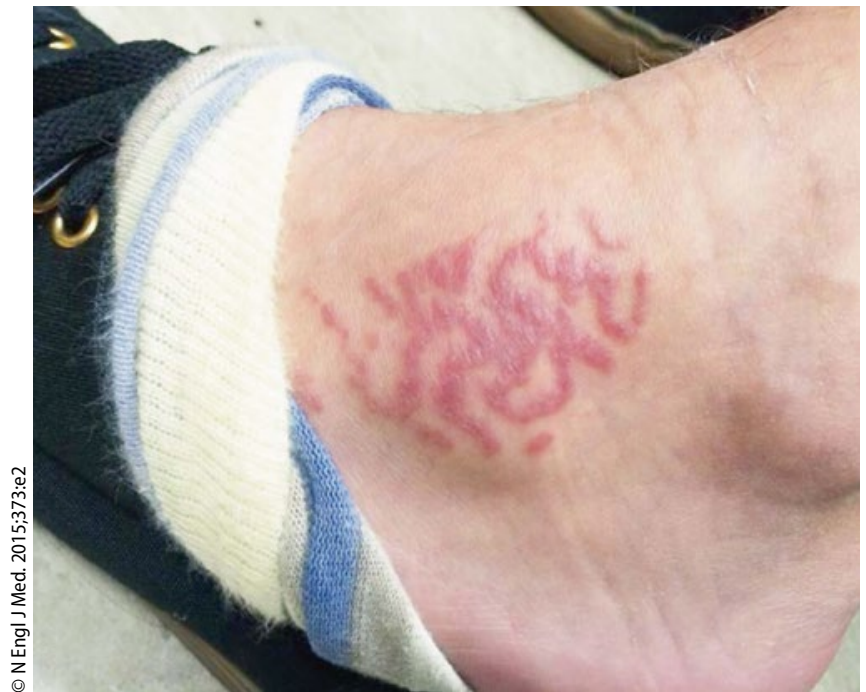

Juckendes Exanthem distal des linken Außenknöchels.
Ein 31-jähriger Mann stellte sich wegen eines juckenden Exanthems am linken Fußrist distal des Außenknöchels vor. Er war an dieser Stelle beim Tauchen in der Karibik mit einer Koralle in Kontakt gekommen. Unmittelbar danach verspürte er an der Kontaktstelle einen brennenden Schmerz, eine Stunde später bemerkte er das starke juckende Exanthem. Die deutlich gerötete Effloreszenz war girlandenförmig konfiguriert. Anamnese und Befund ließen an eine Korallen-Kontaktdermatitis denken.

Zahlreiche Korallenarten sind mit speziellen Organellen ausgestattet, die Toxine absondern. Man unterscheidet eine akute und eine verzögerte Reaktion. Die akute Reaktion besteht in urtikariellen oder vesikobullösen Plaques, die binnen einer Stunde nach Exposition auftreten. Die verzögerte Reaktion ähnelt einer allergischen Kontaktdermatitis in Form einer Hypersensitivitätsreaktion der Typen I und IV und stellt sich klinisch als umschriebene harte Papel dar, die zwei Wochen nach Exposition auftritt. Der Patient wurde mit Triamcinolon-Salbe behandelt. Nach zwei Wochen hatten sich die Effloreszenzen zurückgebildet.

Prof. Dr. H. S. FüeßI 